\title{
Prevalence of skin screening by general practitioners in regional Queensland
}

\author{
Monika Janda, Mark Elwood, Ian T Ring, David W Firman, John B Lowe, Philippa H Youl and Joanne F Aitken
}

QUEENSLAND RESIDENTS have the highest risk of melanoma in the world, carrying a lifetime estimated risk of 1 in 16 for men and 1 in 24 for women. ${ }^{1}$ While incidence has increased in recent years, melanoma mortality has remained relatively stable, ${ }^{2}$ due at least in part to public health campaigns encouraging increased awareness and early diagnosis. ${ }^{3}$

Diagnosis of melanoma depends on the clinical identification of a suspicious lesion. Population screening for melanoma by periodic whole-body skin examination can potentially lead to earlier diagnosis, thinner tumours and fewer deaths, but there is no randomised-trial evidence to support this. ${ }^{4-6}$ Nevertheless, screening of the skin for early signs of cancer is a common clinical procedure.

It was the aim of our study to establish the current prevalence and predictors of skin examination by general practitioners in regional Queensland, in preparation for a randomised controlled trial (RCT) of a community-based screening program for melanoma. ${ }^{7}$

\section{METHODS}

\section{Communities and participants}

Participants in our study were adults aged $\geqslant 30$ years drawn from Queensland communities with populations of between

\section{ABSTRACT}

Objective: To establish the prevalence and predictors of skin screening by general practitioners in regional Queensland.

Design: Questionnaire administered to participants by professional interviewers via telephone.

Participants and setting: Participants were 3100 adults aged $\geqslant 30$ years $(66.9 \%$ overall response rate), selected from residents of 18 regional Queensland communities with populations of between 2000 and 10000 (as recorded in the 1996 Australian census). Within the last 10 communities surveyed, an additional telephone survey of 727 participants evaluated mole density. The survey was conducted between January and October 1998.

Main outcome measure: Prevalence of whole-body skin examinations by GPs.

Results: $11 \%$ of participants reported a whole-body skin examination by a GP during the previous 12 months, and $20 \%$ during the previous 3 years. Men and women reported a similar prevalence of whole-body skin examinations. Factors associated with a significantly increased likelihood of having had a whole-body skin examination within the previous 3 years included a positive attitude towards skin screening, a personal history of non-melanoma skin cancer, a tendency to burn, and having more than four moles on the right upper arm.

Conclusions: A substantial proportion of Queenslanders undergo skin screening. Those at highest risk for skin cancer are more likely to be screened.

MJA 2004; 180: 10-15
2000 and 10000 , as recorded in the 1996 Australian census. In selecting communities, we divided the state of Queensland into four regions (southern coastal, southern inland, northern coastal, northern inland) according to boundaries formed by the Tropic of Capricorn (E-W) and the Great Dividing Range (N-S). Of 107 suitable communities, we selected 44 for
Queensland Cancer Fund, Spring Hill, QLD.

Monika Janda, PhD, Research Fellow; and Research Fellow, School of Public Health, Queensland University of Technology; Philippa H Youl, MPH, Senior Research Officer; Joanne F Aitken, PhD,

Director of Epidemiology; and Associate Professor, School of Population Health, University of Queensland.

National Cancer Control Initiative, Carlton, VIC.

Mark Elwood, MD, Director.

Health Information Centre, Queensland Health, Brisbane, QLD.

lan T Ring, FAFPHM, Principal Medical Epidemiologist/Manager.

Office of Economic and Statistical Research, Queensland Treasury, Brisbane, QLD. David W Firman, MMath, Principal Statistician.

Department of Community and Behavioral Health, University of lowa, lowa City, lowa, USA.

John B Lowe, DrPH, Professor, and Head.

Reprints will not be available from the authors. Correspondence: Associate Professor Joanne F Aitken, Queensland Cancer Fund, PO Box 201, Spring Hill, QLD 4004. joannea@qcfepi.org.au our RCT of melanoma screening, such that no two communities were closer than $50 \mathrm{~km}$ apart by road. Of these, $18 \mathrm{com}$ munities, representing all four geographical regions, were selected for the first phase of the RCT. The 18 communities had a total adult population aged $\geqslant 30$ years of 63035 .

Our survey was conducted by telephone. Telephone numbers were selected at random from a commercially available directory of all telephone numbers in the selected communities. On contacting each household, interviewers asked to speak to the man or woman aged 30 years or more with the most recent birthday. A computerised quota system ensured equal numbers of participants of each sex.

\section{Survey questionnaire}

The survey questionnaire was drafted after consultation with public-health and health-promotion experts and a review of the literature and existing 
questionnaires relating to skin examination. ${ }^{8-12}$ The questionnaire was extensively pre-tested and refined. The reliability of the questionnaire was assessed by re-interviewing 190 participants one month after the first interview. There was good absolute agreement $\left(\mathrm{P}_{\mathrm{A}}\right)$ for the main outcome measure "whole-body skin examination by a medical practitioner during the past three years" $\left(\mathrm{P}_{\mathrm{A}}=86 \%\right)$ and for other questions, including "propensity to sunburn" $\left(\mathrm{P}_{\mathrm{A}}=70 \%\right)$, "mole or spot ever removed" $\left(P_{A}=92 \%\right)$ and "concern about skin cancer" $\left(\mathrm{P}_{\mathrm{A}}=74 \%\right)$.

\section{Interview procedure}

Professional telephone interviewers administered the questionnaire between January and October 1998 (mean interview time, 13 minutes), using a computer-assisted telephone interviewing (CATI) system. A total of 9205 separate households were contacted. Of these, 4555 were ineligible (3709 households had no resident of the required age and sex present at the time of the interview, 525 of the people contacted resided outside the community, 284 could not understand English, 31 had previously completed an interview and 6 indicated that they had black skin). Of the remaining 4650 eligible residents, 987 (21.2\%) refused participation, $444(9.5 \%)$ said they would not be available within the survey period, and 109 (2.3\%) did not receive scheduled callbacks, as the community-specific male/female quota was full. The overall response rate was $66.9 \%$ (range, $60 \%-74 \%$ across communities), with a total of 3110 completed interviews. All responses were entered into the CATI database and automatic internal range checks were conducted.

\section{Information recorded}

Interviewers recorded participants' sociodemographic characteristics, standard melanoma risk factors, degree of concern about skin cancer, perceived likelihood of developing skin cancer in the future, and attitudes towards skin cancer screening. If a participant reported that a GP had found or treated a suspicious skin lesion, details of further management were obtained.

\section{1: Distribution of melanoma risk factors among study participants $(n=3100)^{*}$}

\begin{tabular}{|c|c|c|c|}
\hline & $P$ & $\begin{array}{l}\text { rcentage of participants } \\
\text { having whole-body } \\
\text { skin examination in } \\
\text { previous } 3 \text { years }^{\dagger}\end{array}$ & $\begin{array}{l}\text { Odds ratio } \\
(95 \% \mathrm{Cl})\end{array}$ \\
\hline Hair colour & 0.20 & & \\
\hline Brown/black $(n=2281)$ & & $19.6 \%$ & 1.00 \\
\hline Blond $(n=663)$ & & $21.6 \%$ & $1.13(0.85-1.52)$ \\
\hline $\operatorname{Red}(n=155)$ & & $15.3 \%$ & $0.74(0.45-1.23)$ \\
\hline
\end{tabular}

Skin colour

0.65

Brown/olive/Asian $(n=466)$

Medium $(n=764)$

1.00

Fair $(n=1868)$

$20.0 \%$

$0.88(0.59-1.32)$

Eye colour

Brown/black $(n=924)$

Green/grey $(n=1105)$

Blue $(n=1057)$

Tendency to burn after 30 minutes of unprotected skin exposure

Always tan without burning $(n=128)$

Tan slightly without burning ( $n=642)$

Burn then $\tan (n=1547)$

Always burn without tanning $(n=725)$

Ability to tan

$16.8 \%$

$21.2 \%$

$0.97(0.64-1.47)$

0.23

Deep $\tan (n=846)$

$18.7 \%$

1.00

Moderate $\tan (n=1199)$

Slight $\tan (n=636)$

$18.0 \%$

$0.95(0.76-1.19)$

Never $\tan (n=330)$

$21.5 \%$

$1.20(0.94-1.52)$

$26.5 \%$

$1.57(0.99-2.48)$

Spot/mole removed in the past

No $(n=1427)$

$14.0 \%$

1.00

Yes $(n=1673)$

$24.9 \%$

$2.03(1.48-2.79)$

Personal history of melanoma

No $(n=2985)$

$19.3 \%$

1.00

Yes $(n=113)$

$34.5 \%$

$2.20(1.24-3.92)$

Personal history of non-melanoma skin cancer

No $(n=2867)$

$18.2 \%$

1.00

Yes $(n=233)$

$35.5 \%$

$2.47(1.64-3.72)$

Family history of melanoma

No $(n=2250)$

0.31

Yes $(n=762)$

$19.1 \%$

1.00

$22.7 \%$

$1.24(0.79-1.94)$

Family history of non-melanoma

skin cancer

No $(n=2325)$

$18.7 \%$

1.00

Yes $(n=775)$

$23.4 \%$

$1.32(0.92-1.91)$

* Numbers in column 1 categories do not always add up to 3100 because of missing responses for some questions.

†Percentages have been adjusted to correct for population and cluster sampling. 


\section{Prevalence of skin screening by GPs}

To assess the prevalence of whole-body skin examination, participants were asked, "In the past 12 months/3 years, has your GP deliberately checked the skin on your whole body? Usually this would involve taking your clothes off, at least down to your underwear (ie, bra and underpants)". To assess part-body skin examination, participants were asked, "In the past 12 months, has your GP deliberately checked any part of your skin?" Answers were recorded as "yes", “no", or “don't know”.

\section{Additional information on melanoma risk factors}

In the last 10 communities surveyed, all participants were asked if they would agree to participate in a second, more detailed melanoma risk-factor survey to be held within 2-3 weeks of the first. Most participants (812 [95\%]) agreed, and 727 of these were recontacted within the survey period. Before their second interview, these participants were mailed a booklet containing pictures of mole density and freckling and a stencil with a $2 \mathrm{~mm}$-diameter circle to measure moles on the right upper arm. Participants were asked to place the stencil over their moles and count all moles with a diameter $\geqslant 2 \mathrm{~mm}$.

\section{Statistical analysis}

To allow for the cluster design of the study (communities being the cluster unit), all analyses were conducted using the SUDAAN statistical package. ${ }^{13}$ SUDAAN allows for the changed variation associated with clustered or multistage sample survey data. To ensure that estimates were not unduly biased by disproportionate sampling of community, sex or age group, the data were weighted according to the population distribution (based on the 1996 Australian census).

Standard descriptive statistical analysis and bivariate logistic analyses were performed to establish the prevalence and determinants of whole-body skin examination by a GP within the previous 3 years. All variables with significant $(P<0.05)$ bivariate associations (Wald $\chi^{2}$ ) were entered into a multivariate model, after exclusion of highly correlated measures to avoid collinearity.

\begin{tabular}{|c|c|c|c|}
\hline & $\boldsymbol{P}$ & $\begin{array}{c}\text { Percentage of participants } \\
\text { having whole-body skin } \\
\text { examination in previous } 3 \text { years }\end{array}$ & $\begin{array}{l}\text { Odds ratio } \\
\text { (95\% Cl) }\end{array}$ \\
\hline Some/many freckles as a child & 0.19 & & \\
\hline No $(n=521)$ & & $17.4 \%$ & 1.00 \\
\hline Yes $(n=205)$ & & $20.1 \%$ & $1.19(0.90-1.59)$ \\
\hline Some/many freckles as an adult & 0.008 & & \\
\hline No $(n=611)$ & & $16.9 \%$ & 1.00 \\
\hline Yes $(n=115)$ & & $24.6 \%$ & $1.60(1.10-2.31)$ \\
\hline Presence of moles & 0.001 & & \\
\hline None $(n=140)$ & & $15.0 \%$ & 1.00 \\
\hline Few $(n=426)$ & & $15.8 \%$ & $1.06(0.70-1.61)$ \\
\hline Some/many $(n=159)$ & & $27.8 \%$ & $2.17(1.40-3.38)$ \\
\hline Number of moles on right upper arm & 0.001 & & \\
\hline None $(n=377)$ & & $14.7 \%$ & 1.00 \\
\hline $1-4(n=210)$ & & $14.5 \%$ & $0.99(0.60-1.62)$ \\
\hline$>4(n=138)$ & & $31.8 \%$ & $2.71(1.58-4.63)$ \\
\hline
\end{tabular}

\section{RESULTS}

Results are based on 3100 completed interviews. (Ten of the original 3110 participants were excluded from the analysis, as their ages were unknown.) The demographic characteristics of participants were representative of the Queensland population as described in the 1996 Australian census, with the exception of some groups that were under-represented: women older than 70 years (census, $18.1 \%$; our sample, 9.5\%); people currently not working (census, 47.4\%; our sample, $40.0 \%$ ); and non-Australian citizens (census, $4.4 \%$; our sample, $2.3 \%$ ). (Details of demographic characteristics are available from the authors on request.)

Melanoma risk factors. The prevalence of melanoma risk factors among participants is summarised in Box 1 and Box 2: $25 \%$ of participants reported that they always burn without tanning after 30 minutes of unprotected sun exposure, $53 \%$ reported the removal of a mole or spot in the past, 3\% reported a personal history of melanoma and $9 \%$ reported a personal history of nonmelanoma skin cancer. A quarter of participants reported a family history of melanoma, and a similar number reported a family history of other skin cancer. In the additional, more detailed survey of melanoma risk factors $(n=727), 21 \%$ of participants reported having some or many moles.

Concern about skin cancer and perceived likelihood of developing skin cancer. Almost a quarter (22\%) of participants reported they were concerned about a specific growth or mole at the time of the survey, 39\% were very concerned about skin cancer, and almost a third (32\%) thought it very likely that they would develop skin cancer in the future (Box 3).

Attitude towards skin screening. Attitudes towards skin screening were consistently positive (Box 3). Seventy-nine percent of participants had confidence in their GP's ability to diagnose skin cancer, and only $8 \%$ said that skin checks would be embarrassing.

Prevalence of skin screening. Eleven per cent (95\% CI, 8.7\%-13.9\%) of participants reported that they had had a whole-body skin examination by their GP during the previous 12 months, and $20 \%$ (95\% CI, $16.2 \%-23.4 \%$ ) during the previous 3 years; $31 \%$ of all participants had received a part-body skin examination by their GP in the past 12 


\begin{tabular}{|c|c|c|c|}
\hline \multicolumn{4}{|c|}{ 3: Attitudes and opinions about skin cancer and skin screening $(n=3100)$ * } \\
\hline & $P$ & $\begin{array}{l}\text { Percentage of } \\
\text { participants having } \\
\text { whole-body skin } \\
\text { examination in } \\
\text { previous } 3 \text { years }^{\dagger}\end{array}$ & $\begin{array}{l}\text { Odds ratio } \\
(95.0 \% \mathrm{Cl})\end{array}$ \\
\hline Concern about a specific growth or mole & 0.77 & & \\
\hline Not concerned/don't know $(n=2397)$ & & $19.7 \%$ & 1.00 \\
\hline Very concerned $(n=703)$ & & $20.3 \%$ & $1.04(0.77-1.41)$ \\
\hline Concern about skin cancer & 0.004 & & \\
\hline Not concerned/don't know $(n=1832)$ & & $15.8 \%$ & 1.00 \\
\hline Very concerned $(n=1268)$ & & $26.2 \%$ & $1.90(1.29-2.78)$ \\
\hline Perceived susceptibility to develop skin cancer & 0.001 & & \\
\hline Not likely/don't know $(n=2138)$ & & $16.6 \%$ & 1.00 \\
\hline Very likely to develop skin cancer $(n=962)$ & & $26.5 \%$ & $1.81(1.38-2.37)$ \\
\hline \multicolumn{4}{|l|}{ Opinions about skin cancer and skin screening } \\
\hline Checking my skin regularly is a priority for me & 0.001 & & \\
\hline Strongly disagree/disagree/unsure $(n=911)$ & & $8.8 \%$ & 1.00 \\
\hline Agree/strongly agree $(n=2189)$ & & $26.6 \%$ & $3.77(2.81-5.06)$ \\
\hline $\begin{array}{l}\text { If I saw something suspicious I would } \\
\text { go to the doctor straight away }\end{array}$ & 0.001 & & \\
\hline Strongly disagree/disagree/unsure $(n=443)$ & & $8.5 \%$ & 1.00 \\
\hline Agree/strongly agree $(n=2657)$ & & $22.0 \%$ & $3.02(1.82-5.02)$ \\
\hline $\begin{array}{l}\text { I am confident in my GP's ability to } \\
\text { diagnose skin cancer }\end{array}$ & 0.01 & & \\
\hline Strongly disagree/disagree/unsure $(n=636)$ & & $11.5 \%$ & 1.00 \\
\hline Agree/strongly agree $(n=2464)$ & & $22.0 \%$ & $2.18(1.12-4.26)$ \\
\hline $\begin{array}{l}\text { I am confident I could find something } \\
\text { suspicious on my skin }\end{array}$ & 0.45 & & \\
\hline Strongly disagree/disagree/unsure $(n=599)$ & & $21.6 \%$ & 1.00 \\
\hline Agree/strongly agree $(n=2501)$ & & $19.4 \%$ & $0.87(0.60-1.28)$ \\
\hline Checking my skin would make me anxious & 0.17 & & \\
\hline Strongly disagree/disagree/unsure $(n=2436)$ & & $20.8 \%$ & 1.00 \\
\hline Agree/strongly agree $(n=662)$ & & $15.8 \%$ & $0.71(0.42-1.21)$ \\
\hline Having a skin check would be embarrassing & 0.41 & & \\
\hline Strongly disagree/disagree/unsure $(n=2850)$ & & $20.3 \%$ & 1.00 \\
\hline Agree/strongly agree $(n=250)$ & & $14.2 \%$ & $0.65(0.22-1.93)$ \\
\hline
\end{tabular}

months. In total, $42 \%$ had received some form of skin examination (whole- or part-body) in the previous 12 months. There was no significant difference between men and women, or between younger (30-49 years) and older $(\geqslant 50$ years) participants in the prevalence of whole-body skin examinations (Box 4). Participants 50 years or older reported a part-body skin examination by a GP more frequently than did younger people
(37.6\% [95\% CI, 33.6\%-41.6\%] versus $24.9 \%$ [95\% CI, 21.9\%-27.9\%]; $P=0.001)$. The difference in part-body skin examinations between older and younger participants was observed mainly in men (38.6\% [95\% CI, 31.5\%$45.7 \%]$ in men $\geqslant 50$ years versus $16.4 \%$ [95\% CI, $11.9 \%-20.8 \%$ ] in men 30-49 years; $P=0.01)$. For women, there was no significant difference in prevalence between the two age groups.
Predictors of having had a wholebody skin examination within the previous 3 years. After simultaneous adjustment for all other factors in the multivariate regression model, factors positively associated with having a whole-body skin examination during the previous 3 years were high propensity to develop sunburn, a past history of non-melanoma skin cancer, having more than four moles on the right upper arm, having a positive attitude towards skin screening, and having confidence in the GP's ability to diagnose skin cancer (Box 5). The odds ratios remained essentially unchanged when the analysis was applied to the 727 participants with complete data for moles on the right upper arm, and when age and sex were added to the model (data not shown).

Management of suspicious lesions. Among all survey participants, 657 $(20.8 \%)$ reported that their GP had detected a suspicious freckle, spot or mole in the previous 12 months. This occurred relatively more frequently among people in the older age group than the younger age group (26.3\% [95\% CI, 21.8\%-30.8\%] versus $16.0 \%$ [95\% CI, 12.9\%-19.1\%]; P<0.001). Of the skin lesions detected, 420 were treated immediately, 133 were treated at a later date, 40 were still under surveillance at the time of the survey, 17 were handled by referral to another doctor for treatment, and 28 were still awaiting treatment (for the remaining 19 lesions, participants did not recall how the lesion was treated). Of the lesions treated immediately, 277 were removed through liquid nitrogen or similar substances and 142 were excised (there was one other treated lesion, for which the respondent could not recall the method of treatment). Of the 133 lesions treated at a later date, 30 were treated with liquid nitrogen and 103 were excised. All 40 lesions initially assigned for surveillance were later excised.

\section{DISCUSSION}

More than $11 \%$ of our participants had had a whole-body skin examination by a GP in the previous year, and $20 \%$ in the previous 3 years. In the 12 months before the survey, more than $20 \%$ of all 


\begin{tabular}{|c|c|c|c|c|c|c|c|}
\hline \multicolumn{8}{|c|}{ 4: Proportion of study participants $(n=3100)$ having skin examination by general practitioners* } \\
\hline & \multirow{2}{*}{$\begin{array}{l}\text { Total (\%) } \\
\text { (95\% Cl) }\end{array}$} & \multicolumn{2}{|c|}{$\operatorname{Sex}(\%)(95 \% \mathrm{Cl})$} & \multirow[b]{2}{*}{$P^{\dagger}$} & \multicolumn{2}{|c|}{ Age (\%) $(95 \% \mathrm{Cl})$} & \multirow[b]{2}{*}{$P^{\ddagger}$} \\
\hline & & Men $(n=1555)$ & Women $(n=1545)$ & & $30-49$ years $(n=1759)$ & $\geqslant 50$ years $(n=1341)$ & \\
\hline $\begin{array}{l}\text { Whole-body skin } \\
\text { examination in previous } \\
12 \text { months }\end{array}$ & $\begin{array}{c}11.3 \% \\
(8.7 \%-13.9 \%)\end{array}$ & $\begin{array}{c}10.6 \% \\
(7.8 \%-13.6 \%)\end{array}$ & $\begin{array}{c}11.9 \% \\
(8.5 \%-15.2 \%)\end{array}$ & 0.74 & $\begin{array}{c}12.9 \% \\
(10.6 \%-15.2 \%)\end{array}$ & $\begin{array}{c}9.3 \% \\
(5.3 \%-13.3 \%)\end{array}$ & 0.23 \\
\hline $\begin{array}{l}\text { Whole-body skin } \\
\text { examination in previous } \\
3 \text { years }\end{array}$ & $\begin{array}{c}19.8 \% \\
(16.2 \%-23.4 \%)\end{array}$ & $\begin{array}{c}19.3 \% \\
(16.2 \%-22.4 \%)\end{array}$ & $\begin{array}{c}20.3 \% \\
(15.5 \%-25.0 \%)\end{array}$ & 0.58 & $\begin{array}{c}20.9 \% \\
(17.0 \%-4.8 \%)\end{array}$ & $\begin{array}{c}18.5 \% \\
(13.0-23.9)\end{array}$ & 0.44 \\
\hline $\begin{array}{l}\text { Part-body skin examination } \\
\text { in previous } 12 \text { months }\end{array}$ & $\begin{array}{c}30.9 \% \\
(27.8 \%-34.0 \%)\end{array}$ & $\begin{array}{c}26.9 \% \\
(23.7 \%-30.1 \%)\end{array}$ & $\begin{array}{c}34.9 \% \\
(30.2 \%-39.6 \%)\end{array}$ & 0.01 & $\begin{array}{c}24.9 \% \\
(21.9 \%-27.9 \%)\end{array}$ & $\begin{array}{c}37.6 \% \\
(33.6 \%-41.6 \%)\end{array}$ & 0.001 \\
\hline
\end{tabular}

*Percentages have been adjusted to correct for population and cluster sampling. $\dagger$ Cochrane-Mantel-Haenszel test for difference in proportion between men and women. $\ddagger$ Cochrane-Mantel-Haenszel test for difference in proportion between age categories.

\section{5: Adjusted multivariate logistic regression analysis of factors predicting whole-body skin examination by a GP within the previous 3 years}

\begin{tabular}{|c|c|c|}
\hline & $\boldsymbol{P}$ & $\begin{array}{l}\text { Adjusted odds } \\
\text { ratio* }(95 \% \mathrm{Cl})\end{array}$ \\
\hline \multicolumn{3}{|l|}{ Melanoma risk factors } \\
\hline Tendency to burn after 30 minutes of unprotected sun exposure & 0.05 & \\
\hline Always tan without burning & & 1.00 \\
\hline Tan slightly without burning & & $1.91(0.95-3.85)$ \\
\hline Burn then tan & & $1.90(0.85-4.23)$ \\
\hline Always burn without tan & & $2.47(1.18-5.16)$ \\
\hline Personal history of non-melanoma skin cancer & $<0.01$ & \\
\hline No & & 1.00 \\
\hline Yes & & $2.17(1.23-3.83)$ \\
\hline Number of moles on right upper arm & $<0.01$ & \\
\hline None & & 1.00 \\
\hline $1-4$ & & $0.83(0.53-1.28)$ \\
\hline$>4$ & & $2.34(1.45-3.76)$ \\
\hline Not recorded & & $1.47(0.89-2.44)$ \\
\hline
\end{tabular}

\section{Opinions about skin cancer and skin screening}

Perceived likelihood of developing skin cancer in the future

Not likely, don't know

1.00

Very likely

Concern about skin cancer

Not concerned, don't know

1.00

Very concerned

Checking my skin regularly is a priority for me

Strongly disagree/disagree/unsure

1.00

Agree/strongly agree

If I saw something suspicious I would go to the doctor straight away $<0.01$

Strongly disagree/disagree/unsure

1.00

Agree/strongly agree

$2.47(1.42-4.30)$

I am confident in my GP's ability to diagnose skin cancer

Strongly disagree/disagree/unsure

0.05

Agree/strongly agree

1.00

$2.01(0.93-4.37)$

${ }^{*}$ Adjusted to correct for population and cluster sampling.

participants had had a suspicious lesion detected by their GP, with over $60 \%$ receiving immediate treatment. More than half of all participants had had a mole or spot removed at some time in their lives.

Our study is the first large-scale population-based survey of the prevalence of skin screening by GPs in regional Queensland, an area of high melanoma risk. Ours is one of the few Australian surveys to assess the prevalence of whole-body skin examination on a population basis - most previous surveys have not asked specifically about wholebody skin examination and thus their results are not directly comparable to ours. ${ }^{14-18}$

If skin screening programs are to improve early diagnosis of melanoma, they need to capture those at greatest risk of melanoma - ie, older people (particularly men), people with many moles, with fair pigmentation, who sunburn easily and are unable to tan, and those with a personal or family history of skin cancer. ${ }^{19}$ Our results provide some indication that people with recognised melanoma risk (ie, many moles, a tendency to burn and a personal history of non-melanoma skin cancer) were more likely to have had a whole-body skin examination by a GP in the previous 3 years. However, a limitation of our analysis is that it was based on selfreport, and some results suggest that participants overstated their personal risk of skin cancer and found it difficult to differentiate between a family history of melanoma and a family history of other skin cancers (a problem reported previously in the Queensland 
population ${ }^{20}$ ). Our results may also overestimate the current prevalence of skin screening if those participating were more health-conscious and interested in skin screening than those who refused participation.

A survey of GPs' skin-screening practices $^{21}$ found that doctors strongly supported cancer screening by clinical skin examination and were more likely to include a skin examination as part of a dedicated health check-up for men than for women. However, we did not observe a difference in the number of whole-body skin examinations between men and women.

Part-body examinations were more frequent in the $\geqslant 50$ years age group. Not surprisingly, people aged 50 years or more were treated by a GP for skin lesions more frequently than younger people.

Overall, the high prevalence of skin screening reported in our survey is likely to reflect the high awareness of skin cancer among the public in Queensland, ${ }^{22}$ which is consistent with the high level of concern about skin cancer and with positive attitudes towards skin screening expressed by most of our participants. Another Australian study revealed that most skin excisions for benign pigmented moles are performed to relieve the concerns of worried patients. $^{23}$
The question of whether skin screening does in fact reduce melanoma mortality remains largely untested.

\section{ACKNOWLEDGEMENTS}

We would like to thank Dr Peter Baade for his assistance with statistical calculations.

\section{COMPETING INTERESTS}

None identified.

\section{REFERENCES}

1. Baade $P$, Coory M, Ring I. National health priority cancers in Queensland (1982-1997). Brisbane: Health Information Centre, Queensland Health, 2000.

2. Australian Institute of Health and Welfare and Australasian Association of Cancer Registries. Cancer in Australia 1999. Canberra: AlHW, 2002. (AlHW Catalogue No. CAN 15; Cancer Series No. 20.)

3. Marks R. The changing incidence and mortality of melanoma in Australia. Recent Results Cancer Res 2002; 160: 113-121.

4. Rigel DS, Carucci JA. Malignant melanoma: prevention, early detection, and treatment in the $21 \mathrm{st}$ century. CA Cancer J Clin 2000; 50: 215-236.

5. Rigel DS, Friedman RJ, Kopf AW, et al. Importance of complete skin exam for the detection of malignant melanoma. J Am Acad Dermatol 1986; 14: 857-860.

6. National Health and Medical Research Council. Clinical practice guidelines. The management of cutaneous melanoma. Canberra: NHMRC, 1999.

7. Aitken JF, Elwood JM, Lowe JB, et al. A randomised trial of population screening for melanoma. J Med Screen 2002; 9: 33-38.

8. Aitken JF, Green AC, McLennan R, et al. The Queensland Familial Melanoma Project: study design and characteristics of participants. Melanoma Res 1996; 6: 155-165.
9. Berwick M, Begg CB, Fine JA, et al. Screening for cutaneous melanoma by skin self-examination. J Natl Cancer Inst 1996; 88: 17-23.

10. Youl P, Aitken J, Hayward N, et al. Melanoma in adolescents: a case control study of risk factors in Queensland, Australia. Int J Cancer 2002; 98: 92-98.

11. Whiteman DC, Valery $P$, McWhirter W, Green AC. Risk factors for childhood melanoma in Queensland, Australia. Int J Cancer 1997; 70: 26-31.

12. Green A, McCredie M, MacKie R, et al. A casecontrol study of melanomas of the soles and palms (Australia and Scotland). Cancer Causes Control 1999; 10: 21-25.

13. Shah BV, Barnwell BG, Bieler GS. SUDAAN user's manual. North Carolina: Research Triangle Institute, 1996.

14. Girgis A, Campbell EM, Redman S, Sanson-Fisher RW. Screening for melanoma: a community survey of prevalence and predictors. Med J Aust 1991; 154: 338-343.

15. Hill D, White V, Borland R, Cockburn J. Cancerrelated beliefs and behaviours in Australia. Aust $J$ Public Health 1991; 15: 14-23.

16. Balanda KP, Lowe JB, Stanton WR, Gillespie AM. Enhancing the early detection of melanoma with current guidelines. Aust J Public Health 1994; 18: 420-423.

17. Borland R, Meehan JW. Skin examination for signs of cancer. Aust J Public Health 1995; 19: 85-88.

18. Heywood A, Sanson-Fisher R, Ring I, Mudge P. Risk prevalence and screening for cancer by general practitioners. Prev Med 1994; 23: 152-159.

19. Marks R. Epidemiology of melanoma. Clin Exp Dermatol 2000; 25: 459-463.

20. Aitken JF, Youl P, Green A, et al. Accuracy of casereported family history of melanoma in Queensland, Australia. Melanoma Res 1996; 6: 313-317.

21. Sladden MJ, Ward JE, Del Mar CB, Lowe JB. Skin cancer screening by Australian family physicians: variation with physician belief and geographic locality. Am J Prev Med 1999; 17: 142-146.

22. Del Mar C. Slip, slop, slap and wrap. Should we do more to prevent skin cancer? Med J Aust 1995; 163 511-512.

23. Del Mar C, Green A. Aid to the diagnosis of melanoma in primary medical care. BMJ 1995; 310 : 492-495.

(Received 19 Jun 2003, accepted 11 Nov 2003) 